\title{
DEL JUICIO DE NUREMBERG AL ESTATUTO DE ROMA DE LA CORTE PENAL INTERNACIONAL
}

\author{
José Ricardo Palacio Sánchez-Izquierdo
}

Sumario: Introducción. El Juicio de Nuremberg (Estatuto de Londres de 8-agosto-1945). El Tribunal Militar Internacional de Extremo Oriente. Juicios Locales. Valoración Crítica. De Nuremberg al Estatuto de Roma de la Corte Penal Internacional. ¿Qué cabe esperar del Estatuto de Roma?

\section{Introducción}

«El establecimiento de una Jurisdicción superior, independiente de los Estados, encargada de resolver los litigios de naturaleza criminal que encierren elementos internacionales, sería la expresión más sensible y popular de la justicia penal internacional» ${ }^{1}$.

Estas palabras de Jiménez de Asúa, pronunciadas allá por la década de los años 50, siguen siendo en los albores del siglo XXI un desiderátum aún no alcanzado.

Prescindiendo de antecedentes históricos remotos, sin más valor que el puramente erudito, el primer intento de instaurar una Corte Penal Internacional que depurase responsabilidades de la delincuencia bélica surge, como señala Quintano Ripollés ${ }^{2}$, a la conclusión de la Primera Guerra Mundial, con el Tratado de Versalles y su pretensión de que las potencias vencedoras enjuiciasen al Kaiser Guillermo II y a sus principales colaboradores civiles y militares.

1 Jiménez Asua, Luis: Tratado de Derecho Penal. Tomo II. Editorial Losada (segunda edición) Buenos Aires 1950. Pág. 1.133.

2 Quintano Ripollés, Antonio: Tratado de Derecho Penal Internacional e Internacional Penal. Tomo I. Editorial Consejo Superior de Investigaciones Científicas. Instituto Francisco Vitoria. Madrid 1955. Págs. 397 y siguientes. 
El intento, sin embargo, resultó fallido: el gobierno holandés denegó la extradición de Guillermo II, en cuyo país se había refugiado, y los pocos - 45- criminales de guerra del bando perdedor sometidos a juicio fueron juzgados por el Tribunal Supremo Alemán.

En el interregno entre la primera y la segunda gran guerra se escuchan voces de especialistas -Descamps- e instituciones (International Law Association, Unión Interparlamentaria, Asociación Internacional de Derecho Penal) reclamando la creación de un Tribunal Penal Internacional, sugerencia que es recogida por el acuerdo de la Sociedad de Naciones de 10-septiembre-1934, pero la idea finalmente tampoco fructificó ${ }^{3}$.

Así las cosas, se declara la Segunda Guerra Mundial. Bien avanzada ésta, entre los días 19 y 30 de octubre de 1943, tiene lugar en Moscú una reunión tripartita entre Roosevelt, Churchill y Stalin que, en declaración de fecha 1 de noviembre del mismo año anunciaron su decisión de que los principales criminales de guerra (alemanes, por supuesto), serían juzgados y condenados por una decisión conjunta de los gobiernos aliados, precisándose que a este proceso serían sometidos los principales culpables de los países europeos del Eje, cuyos crímenes no tengan una localización geográfica especial. Quedaban en cambio sujetos a la jurisdicción local de cada país, los perpetrados en sectores concretos, así como los de traición y colaboración con el enemigo $^{4}$.

El escenario quedaba ya configurado: los máximos jerarcas nazis serían juzgados por un Tribunal Internacional aliado; los crímenes de guerra particulares cometidos por los subalternos serían enjuiciados por los Tribunales del lugar de comisión de los hechos.

Fruto de esta decisión es el acuerdo y el Estatuto de Londres, de 8agosto-1945, por el que debía regirse el Tribunal Militar Internacional que juzgase a los grandes criminales de guerra. Era el preludio del «Juicio de Nuremberg».

A título de anécdota cabe señalar que Stalin se había mostrado partidario del fusilamiento de los criminales de guerra alemanes, tan pronto fuesen capturados, fijando incluso la cifra de, al menos, cincuenta mil; pretensión que fue abandonada por la firme oposición de Churchill ${ }^{5}$. Se había evitado la justicia del pelotón de ejecución.

3 JiMÉneZ AsuA, Luis: Op. cit. pág. 1.134.

4 Quintano Ripollés, Antonio: Op. cit. pág. 405 y siguientes.

5 Mayda, Guiuseppe: Nuremberg (1946-1966). Ediciones G.P. Barcelona 1969. Pág. 17. 


\section{EI Juicio de Nuremberg (Estatuto de Londres de 8-agosto-1945)}

Del Estatuto de Londres centraremos la atención en los siguientes aspectos:

1. $\left.{ }^{\circ}\right)$ Quiénes componían el Tribunal Juzgador.

2..$^{\circ}$ Quiénes fueron los juzgados.

3. $\left.{ }^{\circ}\right)$ De qué delitos entendió.

4. $\left.{ }^{\circ}\right)$ Penas aplicables y aplicadas y,

$\left.5 .^{\circ}\right)$ Régimen de recursos contra el fallo.

\section{Composición del Tribunal}

El Tribunal estaba formado por cuatro jueces titulares, uno por cada país signatario (Estados Unidos, Gran Bretaña, Francia y la URSS) y otros cuatro suplentes (art. 2) que no pueden ser recusados ni por el Ministerio Fiscal ni por las defensas de los acusados (art. 3).

Curiosamente, a pesar de su denominación oficial de «Tribunal Militar Internacional», todos sus componentes, salvo los rusos, eran civiles.

\section{Los acusados}

La competencia por razón de la persona del Tribunal se extendía al enjuiciamiento de los principales criminales de guerra de los países europeos del Eje que, actuando en favor de los intereses de dichos países, como individuos o como miembros de organizaciones, hubieran cometido alguno de los crímenes que se reseñan en el Estatuto (art. 6). En suma, el cometido del Tribunal Militar Internacional era el de juzgar a lo que podría definirse sintéticamente como la plana mayor político-militar del Tercer Reich.

Sin embargo, el art. 10 del Estatuto amplía la competencia del Tribunal para el enjuiciamiento de organizaciones o grupos, que podrían ser declarados criminales. Piénsese, por ejemplo, en las S.S. o en las S.A.

\section{De qué delitos entendió}

La competencia por razón de la materia del Tribunal se circunscribía a tres grandes bloques de delitos:

1. $\left.{ }^{\circ}\right)$ Crímenes contra la paz.

$\left.2 .^{\circ}\right)$ Crímenes de guerra y,

3. $\left.{ }^{\circ}\right)$ Crímenes contra la humanidad (art. 6). 
Se describe a continuación el contenido de cada bloque.

Crímenes contra la paz: planeamiento, preparación, iniciación o ejecución de una guerra de agresión o de una guerra en violación de tratados internacionales, acuerdos y seguridades, o la participación en un plan común o en una conspiración para ejecutar cualquiera de los actos precedentes (art. 6.a).

Crímenes de guerra: violaciones de la leyes y de las costumbres de la guerra. Estas violaciones incluyen, pero no están limitadas, asesinatos, maltratamientos y deportaciones para trabajos forzados o para cualquier otro propósito, de poblaciones civiles de territorios ocupados o que se encuentren en ellos; asesinatos o maltratamientos de prisioneros de guerra o de personas en los mares; ejecución de rehenes, despojo de la propiedad pública o privada; injustificable destrucción de ciudades, pueblos y aldeas, devastación no justificada por necesidades militares (art. 6.b).

Crímenes contra la humanidad: asesinatos, exterminación, sometimiento a esclavitud, deportación y otros actos inhumanos cometidos contra cualquier población civil antes o durante la guerra, o persecuciones por motivos políticos, raciales o religiosos, en ejecución o en conexión con cualquier crimen de la Jurisdicción del Tribunal, sean o no una violación de la Legislación interna del país donde hubieran sido perpetrados.

Señala el Estatuto que el haber obrado en cumplimiento de órdenes superiores no será causa de exención de responsabilidad, pudiendo considerarse, facultativamente, a lo sumo como una circunstancia de atenuación de la pena (art. 8).

\section{Penas aplicables}

A tenor del art. 27 «el Tribunal tiene derecho a imponer a un acusado la pena de muerte o cualquier otra pena que considere justa».

\section{Recursos}

Contra la sentencia dictada por el Tribunal Militar Internacional no cabe recurso alguno, ordinario y extraordinario (art. 26). Sin embargo, el art. 29 prevenía que «en caso de condena, las sentencias serán ejecutadas de acuerdo con las órdenes del Consejo de Control de Alemania, el cual puede en cualquier tiempo reducir o modificar las sentencias, pero no aumentar la severidad de las mismas».

El juicio oral se inició el 20-noviembre-1945 y, tras 403 sesiones, se hizo pública la sentencia los días 30 de septiembre y 1 de octubre de 
1946. El fallo fue el siguiente: 12 penas de muerte, 7 penas de prisión comprendidas entre cadena perpetua y 10 años y tres absoluciones por falta de pruebas. Se declaró también la culpabilidad «en grupo» de los dirigentes nazis, de la Gestapo y de las S.S.; por el contrario, no se declaró la culpabilidad del gobierno del Reich, ni del Estado Mayor del Ejército Alemán, ni de las S.A.

\section{EI Tribunal Militar Internacional de Extremo Oriente}

A semejanza del Estatuto de Londres de 8-agosto-1945, se constituyó, meses más tarde, el Tribunal Militar Internacional de Extremo Oriente regulado por el Reglamento de 25-abril-1946, cuya finalidad era la de juzgar a los grandes criminales de guerra japoneses.

Las normas por las que se rigieron los Tribunales de Nuremberg y de Tokio eran muy similares, cabiendo señalar entre ambas las siguientes diferencias: del Tribunal Militar Internacional de Extremo Oriente formó parte un Juez de un país neutral en la contienda (India) y en el Estatuto de este último se simplificó la descripción de las infracciones y se prescindió de la conflictiva figura de la «conspiración», recogida en el Estatuto de Londres, que tantas críticas había suscitado.

De la sentencia dictada por el Tribunal de Tokio el día 12-noviembre 1948 ( 8 penas de muerte, 17 cadenas perpetuas y 2 penas de prisión temporal), discreparon los miembros del Tribunal representantes de India y Francia. No fue juzgado el Emperador del Japón ${ }^{6}$.

\section{Juicios locales}

A raíz de la Segunda Guerra Mundial se enjuiciaron y condenaron también atrocidades de carácter local cometidas con ocasión de ella por los invasores, así como delitos de traición a la patria. Sin embargo, estos procesos que tuvieron lugar en Francia, Bélgica, Holanda, Noruega, Gran Bretaña, Alemania, URSS, Estados Unidos y Japón, no fueron sentenciados por una justicia internacional sino que se sustanciaron ante Tribunales locales.

${ }^{6}$ Quintano Ripollés, Antonio: Op. cit. Tomo I. Págs. 443 y siguientes. JimÉnez Asua, Luis: Op. cit. Tomo II. págs. 1.230 y siguientes. 


\section{Valoración crítica}

El Juicio de Nuremberg suscitó entre los penalistas de la época reacciones diametralmente opuestas. Jiménez de Asúa lo calificó de «rotundo fracaso jurídico» ${ }^{7}$. No es ocioso recordar que el propio Donnedieu de Vabres, juez nombrado por Francia para este proceso, fue muy crítico con la Doctrina sentada por dicho Tribunal en su fallo.

Franco Sodi dijo de él: «es un Tribunal de excepción, ocasional, con motivo de la victoria y que si es capaz de satisfacer el deseo de justicia de algunos, no es visto con absoluta confianza por otros. Un Tribunal de índole semejante puede ser útil para los fines políticos y militares del Estado victorioso, pero difícilmente arraiga en la conciencia universal como un Tribunal con la independencia y neutralidad necesarias para proceder con serenidad y fallar en justicia» ${ }^{8}$.

Por contra, Quintano Ripollés, tras realizar una crítica técnico jurídica del Estatuto de Londres, en el que encuentra graves defectos, acaba señalando que, sin embargo, «es en el terreno de los puros principios donde la sentencia del Tribunal Militar Internacional de Nuremberg puede ostentar mejores timbres de gloria y significado histórico verdaderamente trascendente», para acabar concluyendo que «la significación de Nuremberg en lo internacional general es inmensa y, en lo esencial, de un carácter netamente progresivo» ${ }^{9}$.

Graven concluye su juicio global sobre el proceso de Nuremberg con las siguientes palabras: «el primer Tribunal Penal Internacional de la historia no ha fracasado en su papel de hacer justicia».

Sin entrar en valoraciones políticas sobre la sentencia, un análisis puramente jurídico del contenido del Estatuto de Londres de 8-agosto-1945 descubre en él la vulneración de principios esenciales del Derecho Penal y del Derecho Procesal Penal. Veamos.

\section{Violación del derecho al juez predeterminado por la Ley}

El Tribunal Internacional de Nuremberg fue un órgano judicial excepcional creado «ad hoc» para el enjuiciamiento de unos hechos concretos y de unos personajes concretos.

Se podrá alegar en contra de este argumento que los Jueces alemanes nunca hubieran juzgado a sus compatriotas y, en consecuencia, los

7 JimÉnez AsuA, Luis: Op. cit. Tomo II. Pág. 1.237.

8 Franco Sodi, Carlos: Racismo, Antisemitismo y Justicia Penal. El Tribunal de Nuremberg. Editorial Botas. Méjico 1946. Pág. 148.

9 Quintano Ripollés, Antonio: Op. cit. Tomo I. Pág. 429 y siguientes. 
crímenes de guerra hubiesen quedado impunes. El argumento no carece de fuerza pero no obvia el carácter excepcional del Tribunal de Nuremberg.

\section{Violación del derecho a un juicio imparcial}

El Tribunal de Nuremberg estuvo formado por jueces pertenecientes exclusivamente al bando vencedor. Pretender que, por ejemplo, un juez soviético pueda juzgar imparcialmente a los políticos y militares alemanes responsables de la muerte de millones de conciudadanos rusos, es simplemente quimérico.

\section{Violación del principio de igualdad ante la Ley}

En Nuremberg fueron juzgados solamente los criminales de guerra alemanes. Los crímenes de guerra cometidos por los aliados, tales como el bombardeo de Dresde o los ataques atómicos contra las ciudades de Hiroshima y de Nagasaki permanecieron impunes.

\section{Violación del principio de legalidad}

Uno de los principios esenciales de Derecho Penal es el que proclama que nadie puede ser castigado por un hecho que no tuviera la condición de delito en el momento de su comisión, ni con pena distinta a la señalada por la Ley a tal delito. «Nullum crimen, nulla poena sine praevia lege».

Los reos alemanes fueron juzgados por unos delitos — crímenes de guerra, crímenes contra la paz y crímenes contra la humanidad- que fueron tipificados por el Estatuto de Londres con posterioridad a su comisión. Quebró con ello el postulado básico de la irretroactividad de la Ley Penal desfavorable.

Cabrá contra-argumentar en el sentido de que muchos de los crímenes de guerra y contra la humanidad podían encontrar acomodo en cualquier Código Penal civilizado vigente en el momento de su perpetración.

Se podrá invocar el hecho innegable de que tales crímenes comportaban para cualquier mente humana un reproche ético innegable y que, por lo tanto, no se podía ignorar la ilicitud de la conducta.

Todo ello es cierto, pero no lo es menos que, cuando se prescinde de los principios en aras de la utilidad, la justicia se prostituye y se convierte en un mero instrumento en manos del poderoso para la satisfacción de los intereses de éste. 


\section{Violación del principio de seguridad jurídica}

Una conducta tipificada como delito sólo puede ser sancionada con la pena asignada por la Ley a tal infracción.

El Tribunal de Nuremberg no violó, formalmente, en su sentencia el principio de legalidad de la pena por cuanto impuso a los acusados las sanciones que el Estatuto de Londres había previsto para los delitos perpetrados por los reos: pena de muerte o cualquier otra (art. 26). Ahora bien, establecer para un delito una sanción que puede oscilar, al libre arbitrio del Tribunal, entre la pena capital o una mínima pena de prisión, vulnera los principios de proporcionalidad y de seguridad jurídica.

Seguridad jurídica que también quebranta el Estatuto de Londres al definir los delitos. En efecto, si se observa con detenimiento, en ocasiones es muy difícil por no decir imposible, deslindar ciertos crímenes de guerra de otros crímenes contra la humanidad. Y el hecho no es baladí si se tiene en cuenta que el Tribunal de Nuremberg sólo aplicó la pena de muerte a los reos convictos de crímenes contra la humanidad, no a los responsables solamente de crímenes de guerra.

\section{Otros aspectos cuestionables}

Se ha reprochado también al Estatuto de Londres la introducción de la figura de la conspiración, que dio hartos quebraderos de cabeza a los Juristas, así como de no prever una fase previa de instrucción judicial de la causa, lo que, entre otras cosas, dio lugar a una inusitada duración de las sesiones del juicio oral.

En estas circunstancias es muy difícil formular un juicio global de la justicia de Nuremberg. Cabría decir, a riesgo de simplificar que, con todas sus graves lacras, supuso un avance, un primer y pequeño paso adelante, en orden a la realización de la justicia internacional. Los acusados de Nuremberg, al menos tuvieron derecho a un juicio.

\section{De Nuremberg al Estatuto de Roma de la Corte Penal Internacional}

El precedente del Juicio de Nuremberg y del de Tokio y las críticas vertidas a los Estatutos que rigieron la actuación de ambos tribunales internacionales llevó a la comunidad de naciones a la convicción de que era necesario crear un instrumento jurídico que eliminase los graves defectos en que se había incurrido en ese primer intento de justicia penal internacional.

Si se quería instaurar una verdadera Justicia Penal Internacional era obligado crear una Corte Penal Internacional de carácter permanente e 
imparcial respetuosa con los principios universalmente admitidos en materia de garantías penales y procesales.

En esta convicción, la Asamblea de las Naciones Unidas, el día 12diciembre-1950 acordó crear un Comité que preparase una propuesta de creación de una Corte internacional. El referido Comité terminó su trabajo el 20-agosto-1953. Tendrían que transcurrir 45 años para que la idea fructificase en el Estatuto de Roma de 17-ju1io-1998.

Bien es verdad que en el ínterin han funcionado dos Tribunales Penales Internacionales para la represión de crímenes de guerra en la ex Yugoslavia y en Ruanda. Las experiencias de estas dos Cortes, con resultar interesantes, no son objeto de este trabajo por razones de espacio-tiempo y porque, lo que con él se pretende, en definitiva, es comparar el régimen jurídico del Estatuto de Londres de 1945 con la nueva Corte Penal Internacional creada por el Estatuto de Roma de 1998.

\section{El Estatuto de Roma de la Corte Penal Internacional, de 17-julio-1998}

La Conferencia Diplomática de Plenipotenciarios de las Naciones Unidas sobre el establecimiento de una Corte Penal Internacional, reunida en Roma, aprobaba el día 17 de julio de 1998 el llamado «Estatuto de Roma de la Corte Penal Internacional», cuyo texto consta de un preámbulo y 128 artículos.

Pese a su novedad, el tema ya ha merecido la atención del Profesor Gimeno Sendra, al que dedicó una conferencia que desarrolló en la sede del I. Colegio de Abogados del Señorío de Bizkaia, con motivo del homenaje rendido a la memoria de D. Enrique Ruiz Vadillo ${ }^{10}$. Más recientemente, aunque de forma tangencial, se ha ocupado también de la cuestión Quintero Olivares ${ }^{11}$.

De la lectura del preámbulo y del artículo primero del Estatuto de Roma se deducen ya dos características esenciales del mismo:

1. $\left.{ }^{\circ}\right)$ Lo que se pretende es la creación de una Corte Penal Internacional, de carácter permanente e independiente, que tenga competencia sobre los crímenes más graves de trascendencia para la comunidad internacional $\mathrm{y}$,

10 Un breve extracto de la misma aparece en el Boletín del Colegio de Abogados del Señorío de Bizkaia; noviembre-diciembre 1998; n. ${ }^{\circ} 84$; págs. 14 y 15.

11 Quintero Olivares, Gonzalo. La unificación de la justicia penal en Europa. Revista Penal n. ${ }^{\circ}$ 3. Enero 1999. Nota 4. Págs. 55 y 56. 
2. $\left.{ }^{\circ}\right)$ El carácter complementario de la Corte Penal Internacional respecto de las Jurisdicciones Penales Nacionales, por considerarse deber de todo Estado ejercer su propia Jurisdicción Penal contra los responsables de crímenes internacionales.

Expondremos a continuación, de forma sucinta, la estructura básica del Estatuto de Roma.

\section{La Corte}

La Corte, con sede en La Haya, se compone de 18 magistrados (art. 36), que gozan de independencia en el ejercicio de sus funciones (art. 40). El cargo tiene una duración de 9 años y no es reelegible (art. 36); no pueden ser separados de sus funciones salvo por causas tasadas (art. 46) y pueden ser recusados por las partes cuando razonablemente quepa poner en duda su imparcialidad (art. 41).

La Corte está divida en tres secciones: una sección de cuestiones preliminares, una sección de primera instancia y una sección de apelaciones (art. 34), y sólo es competente para el enjuiciamiento de crímenes cometidos después de la entrada en vigor del presente Estatuto (art. 11).

Compete —en síntesis — a la Sala de cuestiones preliminares:

1. $\left.{ }^{\circ}\right)$ Autorizar o denegar las solicitudes de investigación formuladas por el Fiscal para depurar presuntos crímenes sometidos a la competencia de la Corte.

2. $\left.{ }^{\circ}\right)$ Ejercer como Tribunal de garantías procesales durante la fase de instrucción de la causa, encomendada al Fiscal y,

3..$\left.^{\circ}\right)$ Una vez concluida la fase de instrucción, si el Fiscal presenta acusación contra persona concreta, determinar si hay motivos bastantes para abrir el juicio oral contra ella (arts. 15, 53, 57 y 61).

Corresponde a la Sala de Primera Instancia conocer en juicio oral las causas por delito cuyo enjuiciamiento compete a la Corte (art. 64).

Es competencia de la Sección de Apelaciones revisar, en grado de apelación, las sentencias dictadas por la Sección de Primera Instancia (art. 83), así como entender del recurso extraordinario de revisión (art. 84).

\section{La Fiscalía}

Actúa de forma independiente, como órgano separado de la Corte, y tiene por función recibir información sobre crímenes de la competen- 
cia de la Corte, dirigir la fase de instrucción y ejercitar la acción penal, pudiendo ser recusado un funcionario del Ministerio Fiscal cuando quepa razonablemente poner en duda su imparcialidad (art. 42).

Como síntesis de las disposiciones orgánicas relativas a la Corte cabe subrayar que el Convenio de Roma ha sido muy escrupuloso a la hora de garantizar la imparcialidad y la independencia del Tribunal Penal Internacional, evitando caer en los errores en que incurrió, en este punto, el Estatuto de Londres.

\section{Competencia de la Corte}

Procede ahora examinar la competencia de la Corte por razón de la materia y por razón de las personas.

\section{Por razón de la materia}

Establece el art. 5 del Estatuto que:

«La competencia de la Corte se limitará a los crímenes más graves de trascendencia para la Comunidad Internacional en su conjunto. La Corte tendrá competencia, de conformidad con el presente Estatuto, respecto de los siguientes crímenes:

a) El crimen de genocidio.

b) Los crímenes de lesa humanidad.

c) Los crímenes de guerra y,

d) El crimen de agresión».

La Corte ejercerá competencia respecto del crimen de agresión cuando se apruebe, en el futuro, una disposición en que se definan las modalidades que puede revestir esta infracción penal.

A continuación el Estatuto describe las conductas típicas que integran los crímenes de genocidio, lesa humanidad y de guerra.

El art. 6 dice así:

«A los efectos del presente Estatuto, se entenderá por genocidio cualquiera de los actos mencionados a continuación, perpetrados con la intención de destruir total o parcialmente a un grupo nacional, étnico, racial o religioso como tal:

a) Matanza de miembros del grupo.

b) Lesión grave a la integridad física o mental de los miembros del grupo.

c) Sometimiento intencional del grupo a condiciones de existencia que hayan de acarrear su destrucción física, total o parcial. 
d) Medidas destinadas a impedir nacimientos en el seno del grupo.

e) Traslado por la fuerza de niños del grupo a otro grupo».

A tenor del art. 7:

«A los efectos del presente Estatuto, se entenderá por crimen de lesa humanidad cualquiera de los actos siguientes cuando se cometa como parte de un ataque generalizado o sistemático contra una población civil y con conocimiento de dicho ataque:

a) Asesinato.

b) Exterminio.

c) Esclavitud.

d) Deportación o traslado forzoso de población.

e) Encarcelación u otra privación grave de la libertad física en violación de normas fundamentales de derecho internacional.

f) Tortura.

g) Violación, esclavitud sexual, prostitución forzada, embarazo forzado, esterilización forzada u otros abusos sexuales de gravedad comparable.

h) Persecución de un grupo o colectividad con identidad propia fundada en motivos políticos, raciales, nacionales, étnicos, culturales, religiosos, de género definido en el párrafo tres, u otros motivos universalmente reconocidos como inaceptables con arreglo al derecho internacional, en conexión con cualquier acto mencionado en el presente párrafo o en cualquier crimen de la competencia de la Corte.

i) Desaparición forzada de personas.

j) El crimen de Apartheid.

k) Otros actos inhumanos de carácter similar que causen intencionalmente grandes sufrimientos o atenten gravemente contra la integridad física o la salud mental o física.

2. A los efectos del párrafo primero:

a) Por ataque contra una población civil se entenderá una línea de conducta que implique la comisión múltiple de actos mencionados en el párrafo primero contra una población civil, de conformidad con la política de un Estado o de una organización de cometer esos actos o para promover esa política.

b) El exterminio comprenderá la imposición intencional de condiciones de vida, la privación del acceso a alimentos o medicinas entre otras, encaminadas a causar la destrucción de parte de una población.

c) Por esclavitud se entenderá el ejercicio de los atributos del derecho de propiedad sobre una persona, o de algunos de ellos, incluido el ejercicio de esos atributos en el tráfico de personas, en particular mujeres y niños. 
d) Por deportación o traslado forzoso de población se entenderá el desplazamiento de las personas afectadas, por expulsión u otros actos coactivos, de la zona en que estén legítimamente presentes, sin motivos autorizados por el Derecho Internacional.

e) Por tortura se entenderá causar intencionalmente dolor o sufrimientos graves, ya sean físicos o mentales, a una persona que el acusado tenga bajo su custodia o control; sin embargo, no se entenderá por tortura el dolor o los sufrimientos que se deriven únicamente de sanciones lícitas o que sean consecuencia normal o fortuitas de ellas.

f) Por embarazo forzado se entenderá el confinamiento ilícito de una mujer a la que se ha dejado embarazada por la fuerza, con la intención de modificar la composición étnica de una población o de cometer otras violaciones graves del Derecho Internacional. En modo alguno se entenderá que esta definición afecta a las normas de derecho interno relativas al embarazo.

g) Por persecución se entenderá la privación intencional y grave de derechos fundamentales en contravención del Derecho Internacional en razón de la identidad del grupo o de la colectividad.

h) Por el crimen de Apartheid se entenderán los actos inhumanos de carácter similar a los mencionados en el párrafo 1 cometidos en el contexto de un régimen institucionalizado de opresión y dominación sistemáticas de un grupo racial sobre uno o más grupos raciales y con la intención de mantener ese régimen.

i) Por desaparición forzada de personas se entenderá la aprehensión, la detención o el secuestro de personas por un Estado o una organización política, o con su autorización, apoyo o aquiescencia, seguido de la negativa a informar sobre la privación de libertad o dar información sobre la suerte o el paradero de esas personas, con intención de dejarlas fuera del amparo de la Ley por un período prolongado.

3. ${ }^{\circ}$ A los efectos del presente Estatuto se entenderá que el término "género" se refiere a los dos sexos, masculino y femenino, en el contexto de la sociedad. El término "género" no tendrá más acepción que la que antecede».

Conforme al art. 8:

«1. $\left.^{\circ}\right)$ La Corte tendrá competencia respecto de los crímenes de guerra en particular cuando se cometan como parte de un plan o política o como parte de la comisión en gran escala de tales crímenes.

2. ${ }^{\circ}$ A los efectos del presente Estatuto, se entienden por crímenes de guerra:

a) Infracciones graves de los Convenios de Ginebra de 12 de agosto de 1949 , a saber, cualquiera de los siguientes actos contra per- 
sonas o bienes protegidos por las disposiciones del Convenio de Ginebra pertinente:

- Matar intencionalmente.

- Someter a tortura o a otros tratos inhumanos, incluidos los experimentos biológicos.

- Infligir deliberadamente grandes sufrimientos o atentar gravemente contra la integridad física o la salud.

- Destruir bienes y apropiarse de ellos de manera no justificada por necesidades militares, a gran escala ilícita y arbitrariamente.

- Obligar a un prisionero de guerra o a otra persona protegida a prestar servicio en las fuerzas de una potencia enemiga.

- Privar deliberadamente a un prisionero de guerra o a otra persona de sus derechos a un juicio justo e imparcial.

- Someter a deportación, traslado o confinamiento ilegales. Tomar rehenes.

b) Otras violaciones de las leyes y usos aplicables en los conflictos armados internacionales dentro del marco del derecho internacional, a saber, cualquiera de los actos siguientes:

-Dirigir intencionalmente ataques contra la población civil en cuanto tal o contra civiles que no participen directamente en las hostilidades.

-Dirigir intencionalmente ataques contra objetos civiles, es decir, objetos que no son objetivos militares.

-Dirigir intencionalmente ataques contra personal, instalaciones, material, unidades o vehículos participantes en una misión de mantenimiento de la paz o de asistencia humanitaria de conformidad con la carta de las Naciones Unidas, siempre que tengan derecho a la protección otorgada a civiles u objetos civiles con arreglo al Derecho Internacional de los conflictos armados.

- Lanzar un ataque intencionalmente, a sabiendas de que causará pérdidas de vidas, lesiones a civiles o daños a objetos de carácter civil o daños extensos, duraderos y graves al medio natural que sean claramente excesivos en relación con la ventaja militar general concreta y directa que se prevea.

- Atacar o bombardear, por cualquier medio, ciudades, aldeas, pueblos o edificios que no estén defendidos y que no sean objetivos militares.

- Causar la muerte o lesiones a un enemigo que haya depuesto las armas o que, al no tener medios para defenderse, se haya rendido a discreción.

- Utilizar de modo indebido la bandera blanca, la bandera nacional o las insignias militares o el uniforme del enemigo o de las Naciones Unidas, así como los emblemas distintivos de los Convenios de Ginebra, y causar así la muerte o lesiones graves.

-El traslado, directa o indirectamente, por la potencia ocupante de parte de su población civil al territorio que ocupa o a la de- 
portación o el traslado de la totalidad o parte de la población del territorio ocupado, dentro o fuera de ese territorio.

- Los ataques dirigidos intencionalmente contra edificios dedicados al culto religioso, las artes, las ciencias o la beneficencia, los monumentos, los hospitales y los lugares en que se agrupa a enfermos y heridos, siempre que no sean objetivos militares.

- Someter a personas que estén en poder del perpetrador a mutilaciones físicas o a experimentos médicos o científicos de cualquier tipo que no estén justificados en razón de un tratamiento médico, dental u hospitalario, ni se lleven a cabo en su interés, y causen la muerte o pongan gravemente en peligro su salud.

- Matar o herir a traición a personas pertenecientes a la Nación o al Ejército enemigo.

- Declarar que no se dará cuartel.

- Destruir o confiscar bienes del enemigo, a menos que las necesidades de la guerra lo hagan imperativo.

- Declarar abolidos, suspendidos o inadmisibles ante un Tribunal los derechos y acciones de los nacionales de la parte enemiga.

- Obligar a los nacionales de la parte enemiga a participar en operaciones bélicas dirigidas contra su propio país, aunque hubieran estado a su servicio antes del inicio de la guerra.

- Saquear una ciudad o una plaza, incluso cuando es tomada por asalto.

- Veneno o armas envenenadas.

- Gases asfixiantes, tóxicos o similares o cualquier líquido, material o dispositivo análogo.

-Balas que se abran o aplasten fácilmente en el cuerpo humano, como balas de camisa dura que no recubra totalmente la parte interior o que tenga incisiones.

-Emplear armas, proyectiles, materiales y métodos de guerra que, por su propia naturaleza, causen daños superfluos o sufrimientos innecesarios o surtan efectos indiscriminados en violación del Derecho Humanitario Internacional de los Conflictos Armados, a condición de que esas armas o esos proyectiles, materiales o métodos de guerra sean objeto de una prohibición completa y estén incluidos en el anexo del presente Estatuto en virtud de una enmienda aprobada de conformidad con las disposiciones que, sobre el particular, figuran en los arts. 121 y 123.

- Cometer ultrajes contra la dignidad de la personas, en particular tratos humillantes y degradantes.

- Cometer actos de violación, esclavitud sexual, prostitución forzada, embarazo forzado, definido en el apartado f) del párrafo 2 del art. 7, esterilización forzada y cualquier otra forma de violencia sexual que constituya una violación grave de los Convenios de Ginebra. 
-Aprovechar la presencia de civiles u otras personas protegidas para que queden impunes de operaciones militares determinados puntos, zonas o fuerzas militares.

-Dirigir intencionalmente ataques contra edificios, material, unidades y vehículos sanitarios, y contra personal habilitado para utilizar los emblemas distintivos de los Convenios de Ginebra de conformidad con el Derecho Internacional.

- Provocar intencionalmente la inanición de la población civil como método de hacer la guerra, privándola de los objetos indispensables para su supervivencia, incluso el hecho de obstaculizar intencionalmente los suministros de socorro de conformidad con los Convenios de Ginebra.

- Reclutar o alistar a niños menores de 15 años en las Fuerzas Armadas Nacionales o utilizarlos para participar activamente en las hostilidades.

c) En caso de conflicto armado que no sea de índole internacional, las violaciones graves del art. 3 común a los cuatro Convenios de Ginebra de 12 de agosto de 1949, a saber, cualquiera de los siguientes actos cometidos contra personas que no participen directamente en las hostilidades, incluidos los miembros de las Fuerzas Armadas que hayan depuesto las armas y los que hayan quedado fuera de combate por enfermedad, lesiones, detención o por cualquiera otra causa:

-Actos de violencia contra la vida y la persona, en particular el homicidio en todas sus formas, las mutilaciones, los tratos crueles y la tortura.

- Los ultrajes contra la dignidad personal, en particular los tratos humillantes y degradantes.

- La toma de rehenes.

- Las condenas dictadas y la ejecuciones efectuadas sin sentencia previa pronunciada por un Tribunal constituido regularmente y que haya ofrecido todas las garantías judiciales generalmente reconocidas como indispensables.

d) El párrafo 2 c) del presente artículo se aplica a los conflictos armados que no son de índole internacional, y por lo tanto no se aplica a situaciones de disturbios o tensiones internas, tales como motines, actos aislados y esporádicos de violencia u otros actos de carácter similar.

e) Otras violaciones graves de las leyes y los usos aplicables en los conflictos armados que no sean de índole internacional, dentro del marco establecido de Derecho Internacional, a saber, cualquiera de los actos siguientes:

-Dirigir intencionalmente ataques contra la población civil como tal o contra civiles que no participen directamente en las hostilidades. 
-Dirigir intencionalmente ataques contra edificios, material, unidades y vehículos sanitarios y contra el personal habilitado para utilizar los emblemas distintivos de los Convenios de $\mathrm{Gi}-$ nebra de conformidad con el Derecho Internacional.

-Dirigir intencionalmente ataques contra personal, instalaciones, material, unidades o vehículos participantes en una misión de mantenimiento de la paz o de asistencia humanitaria de conformidad con la carta de las Naciones Unidas, siempre que tengan derecho a la protección otorgada a civiles u objetos civiles con arreglo al derecho de los conflictos armados.

-Dirigir intencionalmente ataques contra edificios dedicados al culto religioso, la educación, las artes, las ciencias o la beneficencia, los monumentos, los hospitales y otros lugares en que se agrupa a enfermos y a heridos, a condición de que no sean objetivos militares.

- Saquear ciudad o plaza, incluso cuando es tomada por asalto.

- Cometer actos de violación, esclavitud sexual, prostitución forzada, embarazo forzado, definido en el apartado f) del párrafo 2 del art. 7, esterilización forzada o cualquier otra forma de violencia sexual que constituya también una violación grave del art. 3 común a los cuatro Convenios de Ginebra.

- Reclutar o alistar niños menores de quince años a las Fuerzas Armadas o utilizarlos para participar activamente en hostilidades.

- Ordenar el desplazamiento de la población civil por razones relacionadas con el conflicto, a menos que así lo exija la seguridad de los civiles de que se trate o por razones militares imperativas.

- Matar o herir a traición a un combatiente enemigo.

- Declarar que no se dará cuartel.

- Someter a las personas que estén en poder de otra parte en el conflicto a mutilaciones físicas o a experimentos médicos o científicos de cualquier tipo que no estén justificados en razón del tratamiento médico, dental u hospitalario de la persona de que se trate ni se lleven a cabo en su interés, y que provoquen la muerte o pongan gravemente en peligro su salud.

- Destruir o confiscar bienes del enemigo, a menos que las necesidades de la guerra lo hagan imperativo.

f) El párrafo 2.e) del presente artículo se aplica a los conflictos armados que no sean de índole internacional y, por consiguiente, no se aplica a situaciones de disturbios y tensiones internas, como motines, actos aislados y esporádicos de violencia u otros actos de carácter similar. Se aplica a los conflictos armados que tienen lugar en el territorio de un Estado cuando existe un conflicto armado prolongado entre las autoridades gubernamentales y grupos armados organizados o entre tales grupos. 
3. Nada de lo dispuesto en los párrafos 2 c) y d) afectará a la responsabilidad que incumbe a todo Gobierno de mantener y restablecer el orden público en el Estado y de defender la unidad e integridad territorial del Estado por cualquier medio legítimo».

Además de estos crímenes que se acaban de señalar, el Tribunal Penal Internacional es también competente para conocer de ciertos delitos contra la Administración de Justicia cometidos contra la propia Corte; así, el art. 70 establece lo siguiente:

«La Corte tendrá competencia para conocer de los siguientes delitos contra la Administración de Justicia, siempre y cuando se cometan intencionalmente:

a) Dar falso testimonio cuando se esté obligado a decir verdad de conformidad con el párrafo 1 del art. 69.

b) Presentar pruebas a sabiendas de que son falsas o han sido falsificadas.

c) Corromper a un testigo, obstruir su comparecencia o testimonio o interferir en ellos, tomar represalias contra un testigo por su declaración, destruir o alterar pruebas o interferir en las diligencias de prueba.

d) Poner trabas, intimidar o corromper a un funcionario de la Corte para obligarlo o inducirlo a que no cumpla sus funciones o a que lo haga de manera indebida.

e) Tomar represalias contra un funcionario de la Corte en razón de funciones que haya desempeñado él u otro funcionario y,

f) Solicitar o aceptar un soborno en calidad de funcionario de la Corte y en relación con sus funciones oficiales».

Se ha cuestionado por algunos si el Estatuto de Roma debió ampliar el catálogo de infracciones competencia de la Corte; así, Gimeno Sendra echa en falta en ese elenco los delitos de terrorismo y narcotráfico.

Desde luego, la competencia por razón de la materia prevista en el Estatuto se halla muy lejos de lo que podría constituir un Código Penal Internacional, tal y como lo concibiera Cherif Basiouni en su obra «Derecho Penal Internacional» ${ }^{12}$.

Con todo, tratándose de una materia en la que se están dando los primeros pasos, no es descabellado que se haya preferido pecar de prudentes, evitando el riesgo de colapsar la Corte Internacional sobrecargándola de competencias.

12 Cherif Basiouni: Derecho Penal Internacional. Con prólogo del Profesor Antonio Beristain. Editorial Tecnos. Madrid 1984. Págs. 101 y siguientes. 


\section{Competencia por razón de la persona}

La competencia por razón de la persona se establece con un doble criterio:

1. $\left.{ }^{\circ}\right)$ La Corte solamente es competente para juzgar a personas naturales. Queda así descartada la posibilidad de declarar criminales a organizaciones o a personas jurídicas, como se preveía en el Estatuto de Londres.

2. $\left.{ }^{\circ}\right)$ Quien quiera que cometa un crimen competencia de la Corte puede ser juzgado por ella (art. 25).

Concretamente el art. 27 dispone que:

«Primero.-El presente Estatuto será aplicable por igual a todos sin distinción alguna basada en el cargo oficial. En particular, el cargo oficial de una persona, sea Jefe de Estado o de Gobierno, miembro de un Gobierno o Parlamento, representante elegido o funcionario de Gobierno, en ningún caso le eximirá de responsabilidad penal ni constituirá per se motivo para reducir la pena.

Segundo.-Las inmunidades y las normas de procedimiento especiales que conlleve el cargo oficial de una persona, con arreglo al derecho interno o al derecho internacional, no obstarán para que la Corte ejerza su competencia sobre ella».

Ya no se distingue entre vencedores y vencidos, como ocurrió en Nuremberg. El paso es importante.

\section{Fuentes de Derecho}

El Estatuto considera como fuentes de derecho:

1..$^{\circ}$ Con carácter prioritario, el propio Estatuto.

2. $\left.{ }^{\circ}\right)$ Subsidiariamente, los Tratados y principios de Derecho Internacional y,

3. $\left.{ }^{\circ}\right)$ En su defecto, los principios generales del Derecho Interno de los sistemas jurídicos del mundo, siempre que no sean incompatibles con el Estatuto ni con las normas o principios de carácter internacional (art. 21).

\section{Principios generales de Derecho Penal}

El Estatuto tiene el acierto de reconocer expresamente los principios esenciales del Derecho Penal: principio de legalidad («nullum crimen, nulla poena sine praevia lege») (arts. 22, 23 y 77); irretroactivi- 
dad de la Ley Penal, salvo que ésta fuese favorable al reo (art. 24); responsabilidad penal individual (art. 25); «nulla poena sine culpa» (arts. 30 y 32); «nulla poena sine judicio» y excepción de «cosa juzgada» (art. 20).

Tras establecer un catálogo de circunstancias eximentes de la responsabilidad criminal (art. 31), el art. 33 regula la eficacia exoneradora del cumplimiento de órdenes, haciéndolo del siguiente modo:

«1. ${ }^{\circ}$ Quien hubiere cometido un crimen de la competencia de la Corte en cumplimiento de una orden emitida por un Gobierno o un Superior, sea militar o civil, no será eximido de responsabilidad penal a menos que:

a) Estuviere obligado por Ley a obedecer órdenes emitidas por el Gobierno o el superior de que se trate.

b) No supiera que la orden era ilícita y,

c) La orden no fuera manifiestamente ilícita.

2..$^{\circ}$ A los efectos del presente artículo, se entenderá que las órdenes de cometer genocidio o crímenes de lesa humanidad son manifiestamente ilícitas».

Por último, se declara la imprescriptibilidad de los crímenes competencia de la Corte.

\section{El proceso ante la Corte}

El proceso ante la Corte puede dividirse en cuatro fases: instrucción, juicio oral, apelación y ejecución de sentencia.

La fase de instrucción tiene por finalidad averiguar si se ha cometido un crimen competencia de la Corte y quién o quiénes son responsables del mismo. En esta fase cobra especial protagonismo la figura del Ministerio Fiscal que es el verdadero promotor de la instrucción, con la intervención para ciertas diligencias de la sección de cuestiones preliminares (arts. 15, 53, 54, 57 y siguientes).

En esta primera fase del procedimiento le asisten al acusado los derechos de no declarar contra sí mismo; no confesarse culpable; no ser objeto de coacciones o torturas; no ser sometido a detención arbitraria; ser informado de la acusación que pesa sobre él; ser asistido de Letrado, así como presentar alegaciones y pruebas (arts. 55, 57 y 61).

Si la Sala de cuestiones preliminares, tras la celebración de una audiencia con intervención del Fiscal y del acusado, estima que existen motivos fundados para creer que el acusado cometió el crimen que se le imputa, remitirá las actuaciones a la Sala de Primera Instancia para celebración de juicio oral (art. 61). 
El juicio oral es público, salvo circunstancias muy especiales (art. 64) y ha de celebrarse con la presencia del acusado (art. 63), rigiendo el principio de presunción de inocencia (art. 66).

Durante el juicio oral asisten al acusado los siguientes derechos: ser oído públicamente; ser informado detalladamente de los cargos que se le imputan; disponer de tiempo y medios suficientes para la preparación de su defensa; comunicarse libre y confidencialmente con su abogado defensor; ser juzgado sin dilaciones indebidas; interrogar a los testigos de cargo; obtener la comparecencia y declaración de testigos de descargo; presentar pruebas pertinentes; ser asistido por un intérprete; guardar silencio y no declararse culpable; no prestar juramento; conocer las pruebas en poder de la acusación, incluso aquéllas que puedan acreditar la inocencia o la atenuación de la responsabilidad del acusado y, finalmente, el derecho a que no se invierta la carga de la prueba, ni le sea impuesta la carga de presentar contrapruebas (art. 67).

Cabe concluir, en pocas palabras, que el procedimiento ante la Corte es un proceso con todas las garantías, escrupulosamente respetuoso con las disposiciones del Pacto Internacional de Derecho Civiles y Políticos (New York, 16 de diciembre de 1966) y con la Convención de Salvaguardia de los Derechos del Hombre y de las Libertades Fundamentales (Roma, 4 de noviembre de 1950) y es homologable con las normas procesales vigentes en los países más garantistas.

El fallo de la Sala de Primera Instancia requiere la mayoría de los Magistrados y contendrá una exposición fundada de la evaluación de las pruebas y las conclusiones; su contenido se hará público (art. 74).

Si el fallo fuese condenatorio, en la sentencia se fijará la pena impuesta (art. 76); para su graduación la Sala tendrá en cuenta la gravedad del crimen y las circunstancias personales del condenado (art. 78).

La Corte, a tenor del art. 77, sólo podrá imponer las siguientes penas:

1..$\left.^{\circ}\right)$ Reclusión por un número de años que no exceda de 30 .

2..$^{\circ}$ Reclusión perpetua, cuando lo justifiquen la extrema gravedad del crimen y las circunstancias personales del condenado.

3. $\left.{ }^{\circ}\right)$ Además de la reclusión cabe imponer una pena de multa y el decomiso de los bienes procedentes del delito.

Obsérvese que en ningún caso cabe imponer la pena de muerte.

Contra la sentencia dictada por la Sala de Primera Instancia tanto el Fiscal como el condenado podrán interponer recurso de apelación ante la Sala de Apelaciones (arts. 81 y 83). 
Dicho recurso habrá de basarse en alguno de los siguientes motivos: vicio de procedimiento, error de hecho, error de derecho o desproporción entre el crimen y la condena.

Se instaura pues el principio de doble instancia, a diferencia de lo dispuesto en el Estatuto de Londres, que imponía la irrecurribilidad del fallo del Tribunal Militar Internacional.

La Sala de Apelaciones, al resolver el recurso, podrá:

1. ${ }^{\circ}$ Confirmar la sentencia.

2. Revocar o enmendar el fallo o la pena.

3. ${ }^{\circ}$ Decretar la celebración de un nuevo juicio en otra Sala de Primera Instancia (art. 83).

Cabe incluso un recurso extraordinario de revisión por motivos tasados, para cuyo conocimiento es también competente la Sala de Apelaciones (art. 84).

Por último, la ejecución de la pena se regula en los arts. 103 a 111 del Estatuto. El proceso de ejecución se rige por las siguientes normas:

1. $\left.{ }^{\circ}\right)$ La pena privativa de libertad se cumplirá en el Estado designado por la Corte.

2. $\left.{ }^{\circ}\right)$ Esta pena tendrá carácter obligatorio para los Estados parte, quienes no podrán modificarla en ningún caso.

3..$\left.^{\circ}\right)$ La ejecución de la pena estará sujeta a la supervisión de la Corte.

4..$^{\circ}$ Las condiciones de reclusión se regirán por la Legislación del Estado de ejecución.

5..$^{\circ}$ La Corte podrá acordar la reducción de la pena cuando el condenado haya cumplido dos terceras partes de la misma, o 25 años de prisión en caso de reclusión perpetua.

Hasta aquí, en breve síntesis, se han desarrollado las líneas maestras del Estatuto de Roma.

\section{¿Qué cabe esperar del Estatuto de Roma?}

La última cuestión a plantear es qué cabe esperar de este Estatuto.

Partiendo del hecho incuestionable de que el Estatuto de Roma de 17-ju1io-1998 supone un paso de gigante respecto del Estatuto de Londres de 8-agosto-1945 y de las normas por las que se rigió el Tribunal Militar Internacional de Extremo Oriente, lo primero que habría que desear es que el Estatuto de Roma entre en vigor. 
Tal cosa sucederá tres meses después de que lo hayan ratificado 60 Estados (art. 126); el Estatuto permanecerá abierto a la firma de los Estados hasta el día 31 de diciembre del año 2000.

Teniendo en cuenta que hasta el mes de diciembre de 1998 no llegaban a 40 los Estados ratificantes, queda la incógnita de si el siglo XXI se iniciará con una nueva justicia penal internacional o, por el contrario, el Estatuto de Roma formará parte de otros intentos fallidos por conseguir una justicia universal.

Sorprende que después de dos grandes confrontaciones mundiales e innumerables guerras de la post-guerra, donde se han cometido atrocidades sin límite y donde han muerto millones de personas, la humanidad no haya tomado aún conciencia clara de que la guerra, en sí misma, es ya un crimen colectivo.

Sorprende igualmente que los conflictos bélicos se hayan convertido en un negocio para las cadenas de televisión que se disputan emitir en vivo y en directo las imágenes más crueles de una contienda.

Sorprende también que potencias que predican la democracia y la fraternidad entre los pueblos olviden esos principios cuando no convienen a sus intereses económicos o geopolíticos.

Sorprende que por razones de política de bloques, las grandes potencias miren hacia otro lado ante conflictos internos en los que se están cometiendo las mayores crueldades.

Sorprende que esos mismos Estados, que ante un asesinato puntual no dudan en aplicar la pena de muerte, no tengan ningún escrúpulo en provocar o en tolerar contiendas en las que hombres, mujeres y niños no beligerantes mueren por millares, a veces salvajemente asesinados.

Sorprende que por ganar un mercado o un escenario de influencia no se repare en medios, aunque el resultado sea un carnicería.

Todo ello lleva a la convicción de que existe una disociación escandalosa entre lo que se estatuye como norma de comportamiento interno y lo que se practica como conducta en el ámbito internacional.

Asiste toda la razón al gran penalista alemán Hans Jescheck cuando afirma que «en tanto las grandes potencias se ocupen solamente de realizar una política imperialista en su propio beneficio, será imposible la creación de un Derecho Internacional Penal» ${ }^{13}$.

$\mathrm{Y}$ es que, a la postre, una verdadera justicia penal internacional sólo será posible el día en que los conceptos de soberanía e independencia sean sustituidos por los de solidaridad e interdependencia.

13 Jescheck Hans: Tratado de Derecho Penal, Parte General. Tomo I. Editorial Bosch. Barcelona 1981. Pág. 165. 